\title{
Articulador de Humanização em Cena: o Diferencial para a Capilarização das Políticas de Humanização Nacional e Estadual nos Territórios
}

\author{
Souza, Rosenéia Braz de \\ Secretaria de Estado da Saúde - Departamento Regional de Saúde III - Araraquara-SP - \\ neia.articuladorahumaniza@gmail.com
}

Introdução o Núcleo Técnico de Humanização da Secretaria de Estado da Saúde de São Paulo, através da linha de ação do Apoio Técnico e Formação em Humanização contemplada na Política Estadual de Humanização publicada em 2012, estabelece a função de Articuladores de Humanização no Estado de São Paulo. Objetivo Delinear e sistematizar as cenas vivenciadas por um Articulador de Humanização do Núcleo Técnico de Humanização da Secretaria de Estado da Saúde de São Paulo, atuando no Departamento Regional de Saúde III de Arararaquara. Metodologia Relato da experiência apontando as considerações e impressões nas experimentações como articulador de humanização desde o processo seletivo e decisório de se inserir na função, até o trabalho em si, dentro dos vários cenários possíveis de inserção e composição no território do DRS III de Araraquara. para tanto, foram utilizados os registros de atividades, as atas e as sínteses avaliativas construídas pelo articulador no período de agosto de 2012 a agosto de 2013, além da experiência viva compartilhada nos encontros. Desenvolvimento CENA 10 despertar pela causa: a inscrição e a seleção. a decisão de me inscrever para o processo seletivo veio de encontro a minha expectativa de acreditar. Acreditar, mesmo sem o embasamento teórico necessário, mas com a vivência prática do cuidado, da gestão e de vida que compõe a minha bagagem. Embora tenham muitas vivências que me fizeram desacreditar de um "SUS que dá certo", neste momento, senti que poderia contribuir para que esta construção fosse possível. Ainda na seleção, que também foi um processo formativo, com produção de discussões e transmissão de conceitos e saberes, o contato com ideais e discursos de pessoas que lutam e difundem a humanização como um processo de mudança e uma política que pode fazer a diferença, me afetou profundamente. Grande expectativa em decorrência do resultado, que apesar de ser candidata única para atuar no DRS III de Araraquara, ficava a dúvida: será que realmente tenho este perfil? Enfim o resultado foi positivo. Muitas dúvidas ocorreram neste início, com especial relevância para a própria compreensão desta nova função e o modo de atuação. o que ficou em destaque no processo de formação foi o diferencial da função de articulador, constituindo-se na flexibilidade e liberdade de percorrer o território e transpor os muros institucionais. Também destaco a potência do trabalho do articulador de conectar a rede dentro dos territórios de atuação e a capacidade de capilarização da política de humanização. o grande desafio, partindo deste primeiro momento é a necessidade de afetar pessoas e a também tomar alguns cuidados que são essenciais, como os processos burocráticos, pensar nas estratégias de aproximação, a intensidade do trabalho, entendendo que quase tudo está contra nós (quem trabalha com a humanização) e a necessidade de identificar momentos de atuação e recuo, uma vez que estaremos entrando em contato com várias realidades, a identificação do campo da autonomia, a necessidade de ter claro o sentido do trabalho e das discussões e também de enxergar o cenário e não somente os sujeitos, com as variáveis visíveis e invisíveis. CENA 2 o trabalho 
para dentro do DRS III: Compreender o território interno do DRS foi o primeiro passo. Conhecer as pessoas, os diversos centros e suas relações, os espaços instituídos, seu papel na rede e a relação com os municípios. Foi um importante processo de mudança, de inserção e de compreensão do meu lugar dentro deste território. Houve vários momentos de tensão nesta inserção, entendendo que a figura do articulador, por ser nova nos processos de trabalho da regional tenderia a este enfrentamento. Estas tensões estão sendo trabalhadas pelos atores envolvidos e a meu ver tem se tornado propulsoras do próprio trabalho do articulador e da humanização. em parceria com o Centro de Desenvolvimento e Qualificação para o SUS (CDQ SUS) muito se tem construído e vem sendo discutido no sentido do desenrolar da política de humanização na ponta e à nível regional, entendendo a complementação do trabalho por ambas as partes. Dentro desta linha vários momentos de parcerias foram possíveis á nível regional, como o momento de acolhimento dos gestores, a oficina de educação permanente e humanização, a retomada das oficinas dos Grupos de Trabalho em Humanização dos Hospitais, dentre outros encontros. As Articuladoras de Atenção Básica também se constituíram em importantes parceiras, principalmente no território dos municípios, onde já tinham certa familiaridade com os atores e os processos de trabalho, bem como a vivência com o próprio SUS, contribuindo enormemente nas discussões e trocas. a diretora do DRS, como importante potência para o trabalho, sempre tem acreditado e apoiado o trabalho da humanização e do articulador. nas reuniões com a equipe técnica, muitos entendimentos do próprio funcionamento da regional vêm sendo compreendidos, contribuindo para o trabalho local, onde várias questões são abordadas e o articulador pode contribuir para o alinhamento dos discursos e a veiculação da informação e orientação. Houve importantes momentos de interação com gestores proporcionados pelo CDQ e com parceria da articulação, como o acolhimento dos gestores que ocorreu em decorrência da mudança de gestão e tinha o objetivo de integrá-los ao DRS através dos seus vários núcleos e centros. na ocasião o articulador pode falar dessa nova função e do seu papel na rede; também teve oportunidade de construir um cordel que contribuiu para a sensibilização e as boas vindas dos gestores e suas equipes. Esse vínculo vem sendo alimentado nas participações constantes nos Colegiados de Gestão Regional, que também é um espaço da gestão e que contribui para suscitar discussões disparadoras e propulsoras do trabalho in loco, como a apresentação pelos gestores das propostas de intenção do trabalho com as Políticas de Educação Permanente e Humanização. nos espaços de discussões das redes de atenção (Cegonha, Psicossocial, Deficiente e Urgência e Emergência) a compreensão do processo contribui para pensar como integrar essas pessoas nos seus territórios, constituindo de fato redes fortes, vivas e potentes, que tenham como foco a melhoria nos processos de atenção e de gestão. o Fórum de Regulação também tem sido um espaço importante de compreensão da dificuldade de integração do vários pontos da rede e da gama de interesses envolvidos neste processo, acarretando em resultados muitas vezes que não atendem as necessidades reais das pessoas. a participação nas oficinas dos GTHs dos Hospitais produzidas pelo CDQ SUS também tem mostrado como potente espaço de discussões de atuação e de revisão de processos de trabalho, bem como de troca de experiências. Outros espaços constituíram-se como importantes para análise de cenários como desencadeadores de conversas no contato com os municípios, como as reuniões da Atenção Básica sobre o Programa de melhoria para a qualidade da Atenção Básica (PMAQ), a Sala de Situação da Atenção Básica, o Comitê Regional de Mortalidade Materna e Infantil, as oficinas para análise dos Mapas de Saúde e outros. Os espaços Macrorregionais ou da RRAS XIII vem se construindo como um processo de ampliação do 
olhar para este amplo território e se constituem em reuniões da Comissão de Integração Ensino e Serviço, dos CDQs dos DRS que compõem este território (Araraquara, Barretos, Franca e Ribeirão Preto), reuniões da Macro onde, além dos CDQs referidos e dos Articuladores, também fazem parte o Núcleo Técnico de Humanização. CENA 3: com o NTH - a construção de uma identidade. Desde o processo de formação, o NTH vem produzindo espaços de conversa mensais, com vários cenários, onde o articulador pode estabelecer um contato mais próximo, trabalhando suas angústias e dúvidas e conectandose as propostas de trabalho para os territórios. a troca com outros articuladores tem se tornado uma importante ferramenta de produção e análise do trabalho e a constituição com os CDQ e Apoiadores do Ministério da Saúde vem se construindo vistas ao desenvolvimento do trabalho e do objetivo comum de todos, que é a humanização da atenção e da gestão no SUS. Importantes momentos de reflexão e da potência do trabalho vêm fazendo parte desses encontros, bem como a instrumentalização e direcionamento do articulador para exercer sua função. CENA 4: nos municípios - conhecendo, produzindo encontros e reflexões. o trabalho com os municípios vem se constituindo a cada dia, à medida que o próprio articulador se apodera do conhecimento teórico e prático, dos processos de trabalho em cada local trabalhado e das possíveis conexões possíveis de serem construídas. na gestão estadual compõe a rede o Hospital Estadual de Américo Brasiliense e o Ambulatório de Especialidades Médicas de Américo Brasiliense que são importantes pontos de referência na rede para os municípios que compõe o DRS III (24 no total). o Hospital também se constitui como referência no Estado para a Humanização e as discussões na Comissão de Humanização do mesmo vem sendo importante espaço de apoio e levantamento da necessidade de articulação com a rede. nos municípios, o foco inicial do trabalho se concentrou em conhecer o território e as pessoas e apresentar-me como articuladora, bem como o meu trabalho. Foram visitados Centros de Saúde, Unidades de Saúde da Família, Centro de Especialidades, Secretarias Municipais de Saúde, Unidades de Atenção Básica, Hospitais e conversado oportunamente com os vários atores (gestores e profissionais de saúde) que compõem esta trama. Este trabalho foi em grande parte realizado conjuntamente com as Articuladoras de Atenção Básica do DRS III. Num segundo momento, o trabalho vem se produzindo com a promoção e estimulação de encontros, vistas a integração das pessoas que compõem essa rede, com a intenção de proporcionar conversas sobre a política de humanização. Vem sendo discutidas questões como o conceito de humanização, a necessidade de uma política de humanização, incentivando neste momento uma importante reflexão sobre o SUS e as fragilidades do sistema, a PNH com os seus princípios, método, diretrizes e dispositivos, a PEH com seu objetivos e suas linhas de ação, bem como suas apostas, enfatizando aqui a necessidade de expansão e regionalização da humanização. Muitas conversas vem sendo produzidas neste caminhar e destaco aqui importantes pontos que foram levantados pelos participantes como as fragilidades e dificuldades de instituir os princípios e diretrizes do próprio SUS, a necessidade de integração e do trabalho em rede, a importância do trabalho em equipe, a necessidade de criação de espaços de conversa, necessidade de aproximação da gestão com a atenção, o modelo de atenção que vem se produzindo e as necessidade de mudança, modelos de gestão, a importância da participação social, acolhimento, acesso e organização do sistema, redes de atenção, ambiência, visita aberta, direito acompanhante, comunicação, autonomia dos sujeitos e interferência política dificultando os processos de trabalho. Resultados Alcançados: a inserção deste novo personagem no território do DRS III vem produzindo um importante processo de constituição e produção do trabalho com a humanização no sentido de compor com os 
diversos centros e núcleos da regional e com o trabalho já construído na regional e nos municípios. o potencial de romper com os muros institucionais e poder estar na ponta dos serviços, com as equipes, vem fortalecendo a capilarização da política de humanização nos municípios. com o incentivo à participação dos diversos atores nos coletivos produzidos nos municípios amplia-se o debate sobre a necessidade de aumentar o grau de comunicação na rede, entendendo a falta de transversalidade como um problema em potencial que dificulta o trabalho e a integração, produzindo vários outros entraves. As funções do articulador de humanização vêm se produzindo à medida que: conhece os territórios e as pessoas, as potências e fragilidades reconhecendo necessidades locais e parceiros para o trabalho; se aproxima das realidades, fazendo ponte com o DRS para compreensão dessas realidades e construção conjunta de demandas regionais; apoia e estimula as iniciativas de trabalho com a humanização nos vários cenários; promove a integração da rede de cuidado através dos seus vários atores; promove a articulação da política de humanização entre os vários pontos da rede; incentiva a produção coletiva e a construção de grupalidades; estimula o planejamento de ações, bem como o monitoramento e a disseminação de resultados positivos. a instrumentalização do articulador através do contato com produções sobre humanização e o Sistema Único de Saúde e a participação em eventos que favorecem uma análise crítica dos processos vem produzindo um refinamento no seu discurso e na abordagem com os municípios, compreendendo melhor os processos de trabalho e o próprio modo e tempo de oferecer e trabalhar o apoio. Considerações Finais: com base nestes momentos de conversa e participações, o trabalho até aqui mostra a importância e necessidade de capilarização da política de humanização, aproximando-a das pessoas e coletivos implicados no processo de produção do cuidado e da saúde. Muitos desafios vem se construindo nesta caminhada como a necessidade de mudanças na forma de fazer gestão e a atenção, a garantia de sustentabilidade da política de humanização, a co-responsabilização dos sujeitos entendidos como protagonistas do trabalho e a criação de grupalidades que fomentem estas discussões e acreditem na política de humanização como necessária para essa (re)construção. Existe também uma necessidade de pensar e concretizar de fato a inserção dos usuários nestes momentos de discussão, entendendo sua voz ativa como importante ferramenta para o planejamento do trabalho, já que sua atuação não ocorre como deveria, bem como do próprio trabalhador da saúde, atores estes, que estão a margem do processo decisório. o articulador precisa estar reafirmando a todo o momento no que acredita e a potência do seu trabalho, tendo em vista que se coloca como importante ativador de análises de processos de trabalho, que muitas vezes geram enfrentamentos e necessidade de mudanças e com isso da saída da zona de conforto, a qual dificulta o olhar ampliado e crítico das situações e produção de sujeitos autônomos e que, no entanto, é um olhar necessário que leva com a política de humanização, um caminho de possibilidades e de vislumbramento de um SUS que queremos de fato produzir.

Souza, Rosenéia Braz de. Articulador de Humanização em Cena: o Diferencial para a Capilarização das Políticas de Humanização Nacional e Estadual nos Territórios. In: Anais do Congresso Internacional de Humanidades \& Humanização em Saúde [= Blucher Medical Proceedings, num.2, vol.1]. São Paulo: Editora Blucher, 2014. ISSN 2357-7282

DOI 10.5151/medpro-cihhs-10563 